\title{
Ionic control of $\beta$ cell function in nesidioblastosis. A possible therapeutic role for calcium channel blockade
}

K J Lindley, M J Dunne, C Kane, R M Shepherd, P E Squires, R F L James,
P R V Johnson, S Eckhardt, E Wakeling, M Dattani, P J Milla, A Aynsley-Green
Institute of Child Health and Great Ormond Street Hospital for Children NHS Trust, London $\mathrm{KJ}$ Lindley E Wakeling M Dattani P J Milla A Aynsley-Green

Department of Biomedical Science, University of Sheffield M J Dunne C Kane

R M Shepherd

P E Squires

Department of Surgery, University of

Leicester

P R V Johnson

The General Hospital, St Helier, Jersey, Channel Islands $S$ Eckhardt

Correspondence to: Dr Keith J Lindley, Institute of Child Health, 30 Guilford Street, London WC1 1EH.

Accepted 21 February 1996

\begin{abstract}
A preterm female infant presented with intractable hypoglycaemia within 10 minutes of delivery. Normoglycaemia could be maintained only by the intravenous infusion of glucose at a rate of 20-22 mg/kg/min. Persistent hyperinsulinaemic hypoglycaemia of infancy was diagnosed from an inappropriately raised plasma insulin concentration $(33 \mathrm{mU} / \mathrm{/})$ at the time of hypoglycaemia (blood glucose $<0.5 \mathrm{mmol} / \mathrm{)})$. Medical treatment with glucagon, somatostatin, and diazoxide led to only a modest reduction in the intravenous glucose requirement; a $95 \%$ pancreatectomy was performed and histological 'nesidioblastosis' confirmed. In vitro electrophysiological studies using patch clamp techniques on isolated pancreatic $\beta$ cells characterised the ionic basis for insulin secretion in nesidioblastosis. The $\beta$ cells were depolarised in low ambient glucose concentrations with persistently firing action potentials; these were blocked reversibly by the calcium channel blocking agent verapamil. Persistent postoperative hyperinsulinaemic hypoglycaemia was treated with oral nifedipine. This increased median blood glucose concentrations from 3.5 to 4.8 mmol/h and increased in duration the child's tolerance to fasting from 3 to 10.5 hours. These data allude to an abnormality in the ionic control of insulin release in nesidioblastosis and offer a new logical approach to treatment which requires further evaluation.

(Arch Dis Child 1996; 74: 373-378)
\end{abstract}

Keywords: nesidioblastosis, $\beta$ cell, calcium channel, hyperinsulinaemic hypoglycaemia.

Hypoglycaemia is the most common metabolic abnormality in childhood and, when severe or recurrent, can cause devastating neurological sequelae. ${ }^{1}$ When due to hyperinsulinism, the consequences of hypoglycaemia are particularly severe, since not only is the brain deprived of glucose, but the excessive secretion of insulin switches off lipolysis and ketogenesis, thereby depriving the brain of a supply of alternative fuels. ${ }^{2}$ Persistent hyperinsulinaemic hypoglycaemia of infancy (PHHI), which is commonly associated with so called nesidioblastosis, ${ }^{3}$ may be extremely difficult to control medically, and various combinations of the therapeutic agents diazoxide, glucagon, and somatostatin have been used in order to restore normoglycaemia. ${ }^{45}$ The degree of success achieved by these agents is variable, and many children require surgery in the form of a subtotal or total pancreatectomy. ${ }^{6}$

Until recently, the pathophysiology of the condition has remained uncertain and controversial. The histological features of nesidioblastosis have been found in pancreases from infants dying from conditions not associated with hypoglycaemia, and severe hyperinsulinism may occur in infants in whom no structural abnormality of the endocrine pancreas can be found. ${ }^{7}$ In vitro studies of isolated islets from pancreases with nesidioblastosis have shown the presence of a regulatory defect in the coupling of extracellular glucose to the secretion of insulin. ${ }^{89}$ The $\beta$ cell ATP dependent potassium channel, $\mathrm{K}^{+} \mathrm{ATP}$, plays a key role in the subcellular mechanisms which regulate insulin secretion. ${ }^{10-13}$ In resting $\beta$ cells open channel events are involved in controlling the cell membrane potential. $\mathrm{K}^{+}$ATP channel inhibition following glucose metabolism leads to depolarisation of the $\beta$ cell. This leads to activation of voltage dependent L-type calcium channels and the net influx of calcium through these channels leads to an increase in cytosolic calcium concentration. ${ }^{14} 15 \mathrm{~A}$ rise in intracellular calcium is a prerequisite for exocytosis and the secretion of insulin.

Recent advances in the molecular genetics of PHHI have provided new insight into the pathophysiology of this disease. ${ }^{16-19}$ These developments have highlighted the fundamental importance of the ionic control of insulin secretion.

We report for the first time a study of electrical events in isolated intact $\beta$ cells from a premature infant with PHHI. These in vitro studies were followed by a successful clinical trial of the use of the calcium channel blocking agent nifedipine. 


\section{Methods}

ISLET ISOLATION

Islets were isolated from a portion of the resected pancreas using a modification of established procedures for the isolation of adult human islets from heart-beating cadaver organs. ${ }^{20}$ In brief, a portion of the excised pancreas was cut into small pieces and incubated at $38^{\circ} \mathrm{C}$ in Hanks solution containing 3 $\mathrm{mg} / \mathrm{ml}$ Clostridium histolyticum collagenase (Boehringer Mannheim type P). Digestion of the pancreas was assessed by the appearance of freely liberated diphenylthiocarbazone stained islets; digestion was stopped by using an excess of fetal calf serum. Isolated cleaved islets were purified using a small scale Ficoll ${ }^{\mathrm{TM}}$ density gradient. Despite these procedures the yield of isolated islets was low (the $2 \mathrm{~g}$ of pancreatic tissue available to us produced only 200-300 islets). Once isolated, the islets were maintained for a short period of time (2-7 days) under standard tissue culture conditions at $37^{\circ} \mathrm{C} . .^{20}$

\section{MICROFLUORIMETRY}

This was performed on isolated intact islets loaded with the $\mathrm{Ca}^{2+}$ fluorescent probe fura-2 using dual excitation single emission spectroscopy as described previously. ${ }^{20}$ An increase in the ratio of fluorescence at $350 / 380 \mathrm{~nm}$ corresponds to an increase in the intracellular calcium concentration $\left(\left[\mathrm{Ca}^{2+}\right]_{\mathrm{i}}\right)$. Estimates of $\left[\mathrm{Ca}^{2+}\right]_{\mathrm{i}}$ were made using an in vitro calibration procedure.

\section{ELECTROPHYSIOLOGY}

Electrophysiology data were obtained from intact primary cultured $\beta$ cells using patch clamp techniques as described previously. ${ }^{21}$ The composition of the solutions used to fill the patch clamp pipette and the bath contained (mmol/l): $\mathrm{NaCl} 140, \mathrm{KCl} 4 \cdot 7, \mathrm{MgCl}_{2} 1 \cdot 13$, glucose $2 \cdot 5,4$-(2-hydroxyethyl)-1-piperazineethanesulphonic acid (HEPES) 10 , and $\mathrm{CaCl}_{2}$ $2 \cdot 5(\mathrm{pH} 7 \cdot 4)$.

For display purposes the current trace has been low pass filtered at a cut off frequency. of $300 \mathrm{~Hz}$. Upward deflections from the baseline represent outward current events.

METABOLIC FASTING PROTOCOL

The infant underwent formal metabolic fasts before and after the start of nifedipine, according to a standardised protocol. In brief, each fast began with a feed of $25 \mathrm{ml} / \mathrm{kg}$ of the same formula milk feed (a term infant formula fortified with additional glucose polymer to a total concentration of $12 \%$ carbohydrate). Thereafter blood glucose was estimated on capillary blood samples every 30 minutes using a Glucometer 4 meter and Glucotide test strips (Bayer). When the capillary sample fell to $2 \cdot 6$ $\mathrm{mmol} / 1$ or lower a whole blood glucose was measured in the laboratory within 5 minutes. The fast was terminated if blood glucose in the laboratory was below $2.6 \mathrm{mmol} / \mathrm{l}$, and the infant fed. On termination of the fast additional blood was drawn for simultaneous measurement of glucose, insulin, and other metabolic intermediates.

\section{STATISTICS}

Median blood glucose concentrations were compared using a Kruskal-Wallis one way analysis of variance (ANOVA) on ranks, and individual comparisons made using a Mann Whitney rank sum test. Parametric data were compared using Student's unpaired $t$ test.

\section{Case report}

The patient is the first child of non-consanguineous Caucasian parents and was born at $31^{+5}$ weeks gestation following an emergency lower segment caesarean section because of moderately severe pre-eclampsia. No cardiorespiratory resuscitation was required, but a blood glucose concentration of $<0.5 \mathrm{mmol} / \mathrm{l}$ was documented at 10 minutes of age. The child was given an intravenous bolus of glucose, but recurrent hypoglycaemia could only be prevented by the administration of a continuous intravenous infusion of glucose at a rate equivalent to not less than $20-22 \mathrm{mg}$ glucose $/ \mathrm{kg} / \mathrm{min}$. With the start of a concurrent intravenous infusion of glucagon $(2 \mathrm{mg} / \mathrm{d})$, the glucose requirement was transiently reduced to $18 \mathrm{mg} / \mathrm{kg} / \mathrm{min}$.

She was noted to have dysmorphic features (high arched palate, hypertelorism, brachycephaly) with bilateral corneal clouding. Ophthalmological assessment revealed bilateral glaucoma and anterior segment dysgenesis consistent with the Axenfeld's anomaly (posterior embryotoxon, iris filaments, and bands with or without glaucoma). ${ }^{22}$ Systemic examination of the child revealed the presence of a patent ductus arteriosus.

Her mother also suffered from Axenfeld's syndrome and had an atrial septal defect.

At the age of 4 days, the patient was transferred to Great Ormond Street Hospital for further evaluation. A diagnosis of hyperinsulinaemic hypoglycaemia was made by demonstrating inappropriately raised levels of plasma insulin (16-33 mU/l) with suppression of lipolysis and ketogenesis (plasma free fatty acid and blood total ketone body levels of $0 \cdot 11$ $\mathrm{mmol} / \mathrm{l}$ and $0.06 \mathrm{mmol} / \mathrm{l}$ respectively) at the time of spontaneous hypoglycaemia (blood glucose level $<0.5-1.0 \mathrm{mmol} / \mathrm{l}$ ) In an attempt to achieve normoglycaemia, a somatostatin infusion $(0.25 \mu \mathrm{g} / \mathrm{kg} / \mathrm{h})$ and oral diazoxide (10 $\mathrm{mg} / \mathrm{kg} / \mathrm{d}$ ) with concurrent hydrochlorothiazide were begun. However, stabilisation of her blood glucose control proved to be exceedingly difficult and could only be achieved with a combination of diazoxide $(20 \mathrm{mg} / \mathrm{kg} / \mathrm{d})$, hydrochlorothiazide, somatostatin $(0.3 \mu \mathrm{g} / \mathrm{kg} / \mathrm{h})$ and glucagon $(5 \mu \mathrm{g} / \mathrm{kg} / \mathrm{h})$. Hydrocortisone $50 \mathrm{mg} /$ $\mathrm{m}^{2} / \mathrm{d}$ was also given to cover any effect of somatostatin on ACTH secretion. This combination eventually led to a reduction by day 36 in glucose requirements to $11-17 \mathrm{mg} / \mathrm{kg} / \mathrm{min}$, given as a combination of continuous enteral feeding through a nasogastric tube and intravenous glucose. Her progress was complicated 


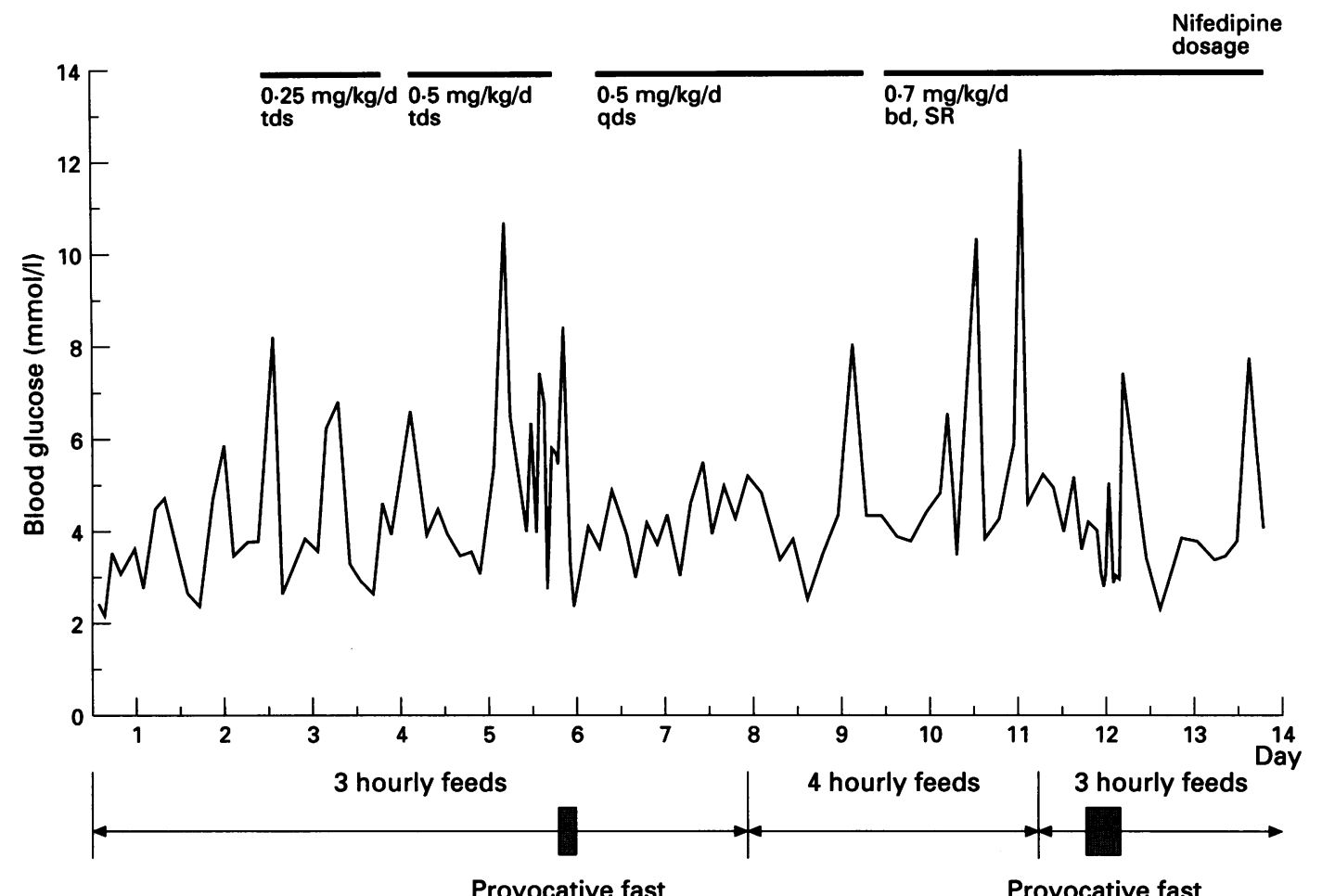

Figure 1 Blood glucose concentrations (measured on capillary blood samples using a Glucometer 4 blood glucose meter) before and after treatment with nifedipine. $b d=t w o$ divided doses; $t d s=$ three divided doses; $q d s=$ four divided doses; $S R=$ slow release preparation of nifedipine.

by a haemodynamically significant patent ductus arteriosus which was surgically ligated at 21 days of age.

Ongoing difficulties with unpredictable episodes of hypoglycaemia despite this maximal medical therapy led to a $95 \%$ pancreatectomy, performed at the age of 50 days. The histopathological appearance of the pancreas was consistent with that of 'nesidioblastosis', with hyperplasia of the $\beta$ cells and ducto-insular endocrine cell proliferation. ${ }^{23}$

Blood glucose concentrations appeared to be stable postoperatively on a three hourly feeding regimen without any medical adjuncts, and with an assessed glucose intake of 8 $\mathrm{mg} / \mathrm{kg} / \mathrm{min}$. She was therefore transferred back to her local hospital to monitor the natural history of the condition. During the next eight weeks she developed recurrent episodes of hypoglycaemia associated with an increase in her glucose requirement to $13 \mathrm{mg} / \mathrm{kg} / \mathrm{min}$ and a reduced tolerance to fasting.

She was readmitted to Great Ormond Street Hospital at the age of 5 months for a further assessment. A tolerance of three hours of fasting before the onset of hypoglycaemia was confirmed. Our in vitro studies (see below) performed on islets isolated from the infants pancreatectomy specimen had shown that $\beta$ cell calcium dependent action potentials could be blocked with verapamil. We therefore undertook a therapeutic trial of the calcium channel blocking agent nifedipine rather than proceeding directly to a total pancreatectomy.

After obtaining parental consent and after a 48 hour period in which blood sugars were measured preprandially, the short acting form of nifedipine was started at a dosage of 0.25 $\mathrm{mg} / \mathrm{kg} / \mathrm{d}$, given at eight hourly intervals. No discernible side effects on blood pressure or on cardiac conduction were noted; no increase in blood glucose concentrations was seen (fig 1, table). On increasing the dose to $0.5 \mathrm{mg} / \mathrm{kg} / \mathrm{d}$ there was a highly significant increase in blood glucose concentrations (median $3.5 \mathrm{mmol} / \mathrm{l}$ pre-nifedipine, $4.8 \mathrm{mmol} / \mathrm{l}$ on nifedipine) (table). Fasting tolerance increased from $3 \cdot 3$ hours to 4.5 hours on this regimen. Problems were encountered with precipitous hypoglycaemia as the medication wore off and these problems were not overcome by giving the nifedipine in four divided doses. An increase in nifedipine dose to $0.7 \mathrm{mg} / \mathrm{kg} / \mathrm{d}$ and conversion to a slow release formulation dramatically increased her fast tolerance to over 10.5 hours (fig 2), with an increase in the median pre-

Median preprandial blood glucose concentrations over 48 hour periods before and after treatment with nifedipine. Periods during which the infant underwent diagnostic fasting are excluded

\begin{tabular}{|c|c|c|c|c|c|c|}
\hline & $\begin{array}{l}\text { Pre- } \\
\text { nifedipine }\end{array}$ & $0.25 \mathrm{mg} / \mathrm{kg} / 24 \mathrm{~h}$ & $0.5 \mathrm{mg} / \mathrm{kg} / 24 \mathrm{~h}$ & $\begin{array}{l}0.7 \mathrm{mg} / \mathrm{kg} / 24 \mathrm{~h} \\
\text { (initial } 48 \mathrm{~h} \text { period) }\end{array}$ & $\begin{array}{l}0.7 \mathrm{mg} / \mathrm{kg} / 24 \mathrm{~h} \\
\text { (subsequent period) }\end{array}$ & $\begin{array}{l}0.7 \mathrm{mg} / \mathrm{kg} / 24 \mathrm{~h} \\
(1 \mathrm{month} \text { later })\end{array}$ \\
\hline $\begin{array}{l}\text { Median preprandial } \\
\text { glucose (mmol/1) } \\
\text { Interquartile range } \\
\text { n } \\
\text { Feed interval (h) }\end{array}$ & $\begin{array}{l}3 \cdot 5 \\
3 \cdot 0 \text { to } 4 \cdot 2 \\
14 \\
3 \\
a^{3}\end{array}$ & $\begin{array}{l}3 \cdot 8 \\
3 \cdot 1 \text { to } 6 \cdot 3 \\
13 \\
3 \\
b\end{array}$ & $\begin{array}{l}4 \cdot 8 \\
3 \cdot 8 \text { to } 6 \cdot 6 \\
14 \\
3 \\
c\end{array}$ & $\begin{array}{l}4 \cdot 5 \\
3 \cdot 8 \text { to } 5 \cdot 4 \\
14 \\
4 \\
d\end{array}$ & $\begin{array}{l}4 \cdot 2 \\
3 \cdot 8 \text { to } 5 \cdot 2 \\
14 \\
e^{3}\end{array}$ & $\begin{array}{l}4 \cdot 5 \\
4 \cdot 0 \text { to } 5 \cdot 2 \\
24 \\
4 \\
f\end{array}$ \\
\hline
\end{tabular}

Kruskal-Wallis one way ANOVA on ranks: statistically significant difference in groups $(p<0.02)$.

Mann Whitney rank sum test: $\mathrm{a} v \mathrm{~b}, \mathrm{p}=0.33$; $v$ c, $\mathrm{p}<0.005$; $\mathrm{a} v \mathrm{~d}, \mathrm{p}<0.005 ; \mathrm{a} v \mathrm{e}, \mathrm{p}<0.02 ; \mathrm{a} v \mathrm{f}, \mathrm{p}<0.008$. 


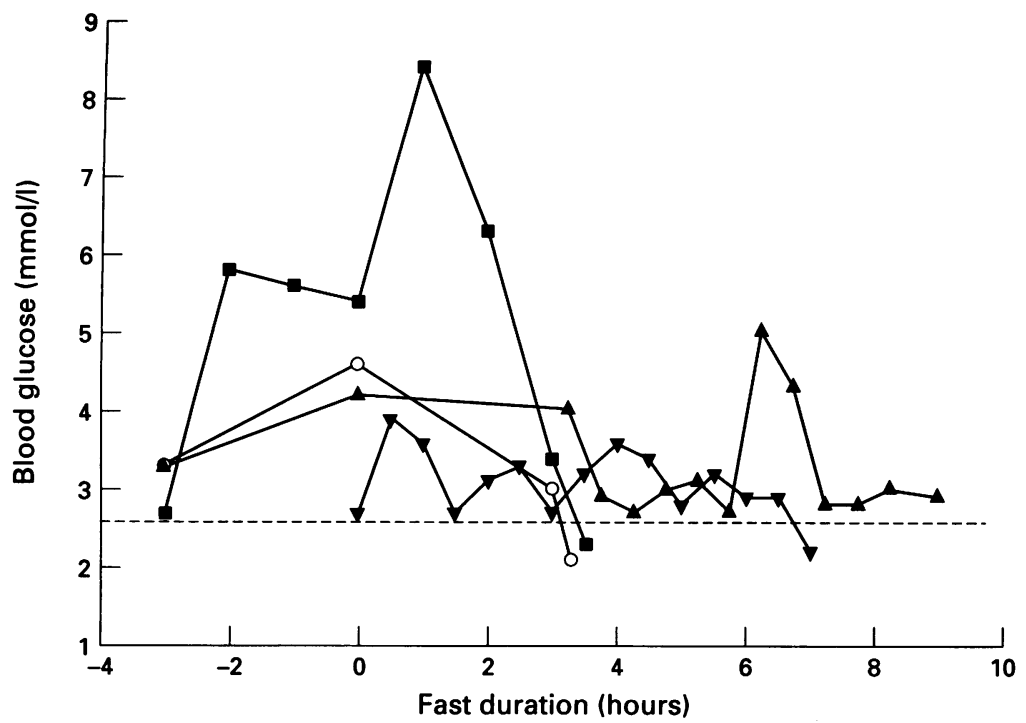

Figure 2 Blood glucose concentrations before and during fasting before and after the start of nifedipine treatment. Fasts were started at time $=0$ on the graph. The dotted line represents a glucose concentration of $2.6 \mathrm{mmol} / \mathrm{which}$ was the concentration below which fasts were terminated. 0 pre-nifedipine; nifedipine $0.5 \mathrm{mg} / \mathrm{kg} / \mathrm{d}$ in three divided doses; $\Delta$ nifedipine SR (slow release) $0.7 \mathrm{mg} / \mathrm{kg} / \mathrm{d}$ in two divided doses; $\nabla$ nifedipine SR 0.7 $\mathrm{mg} / \mathrm{kg} / \mathrm{d}$ in two divided doses after one month on treatment.

prandial glucose concentration to $4.5 \mathrm{mmol} / \mathrm{/}$ during the first 48 hours despite a lengthening of feed interval from three to four hours. A fall in median blood glucose concentration to $4.2 \mathrm{mmol} / \mathrm{l}$ during a subsequent period of treatment (following the metabolic fast period) was associated with problems of vomiting due to gastro-oesophageal reflux (table).

The patient was discharged home on oral nifedipine and four hourly nasogastric feeds, with home monitoring of blood glucose. She was subsequently readmitted to Great Ormond Street Hospital for insertion of a ventriculo-atrial shunt at the age of 6 months. Her blood glucose profiles during this admission were normal on four hourly feeds (median preprandial blood glucose $4.5 \mathrm{mmol} / \mathrm{l}$ ) and her fast tolerance was seven hours. She maintained normoglycaemia following the introduction of overnight fasting of five to six hours.

\section{Results of in vitro studies on isolated intact $\beta$ cells}

In vitro studies upon isolated nesidioblastotic $\beta$ cells were carried out using our previously validated patch clamp and microfluorimetry techniques. ${ }^{2021}$ Using the cell attached patch configuration the basic electrophysiological 'profile' of the nesidioblastotic $\beta$ cells was markedly different from that seen in both normal human adult and rodent (fetal, neonatal, and adult) $\beta$ cells. ${ }^{11} 122425$ The nesidioblastotic $\beta$ cells displayed a number of novel electrophysiological properties associated with $\mathrm{K}^{+}{ }_{\text {ATP }}$ channel dysfunction. ${ }^{26}$ Of particular interest here is the observation that the patient's $\beta$ cells were constantly depolarised and persistently firing $\mathrm{Ca}^{2+}$ action potentials (fig 3). These action potentials arise from calcium entry through voltage activated L-type calcium channels. One consequence of this persistent electrical activity is that intracellular calcium concentrations are increased approximately twofold when compared with normoglycaemic human $\beta$ cells: $149 \mathrm{nmol} / 1$ (95\% confidence interval 127 to 171 ), $\mathrm{n}=16, v 79$ $\mathrm{nmol} / 1$ (68 to 90), $\mathrm{n}=141 ; \mathrm{p}<0.0001$, Student's unpaired $t$ test. The action potentials were rapidly and reversibly terminated by exposure to the voltage gated calcium channel blocker verapamil $(10 \mu \mathrm{mol} / \mathrm{l})$ (fig 3$)$.

Human PHHI $\beta$ cell

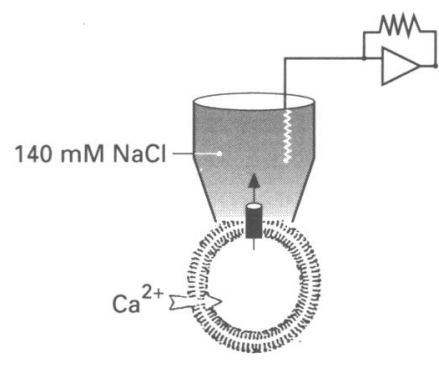

$10 \mu \mathrm{M}$ verapamil

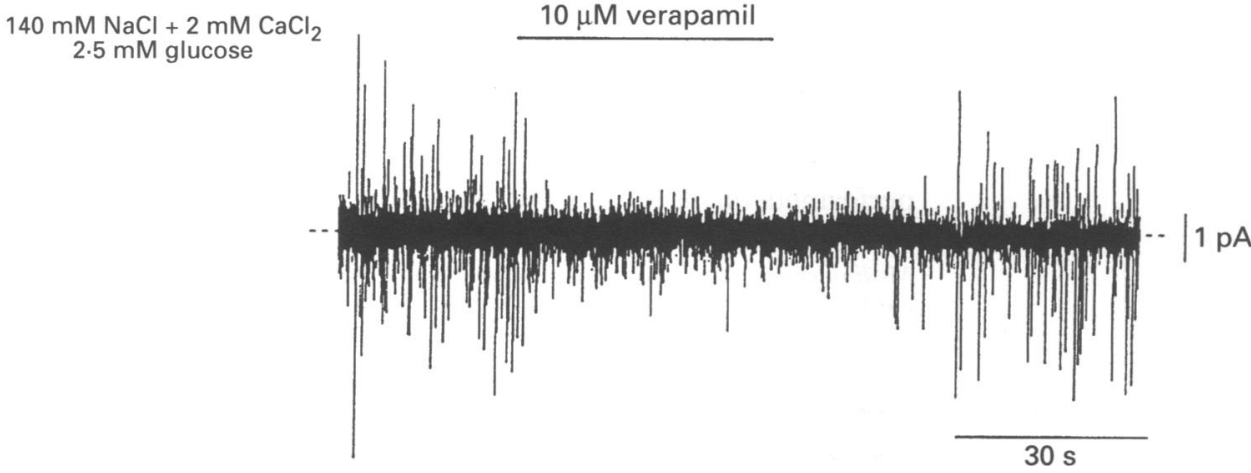

Figure 3 Cell attached patch recording of an intact isolated PHHI $\beta$ cell (configuration shown on insert cartoon). The recording shows spontaneous electrical activity from the cell associated with the appearance of $\mathrm{Ca}^{2+}$ dependent action

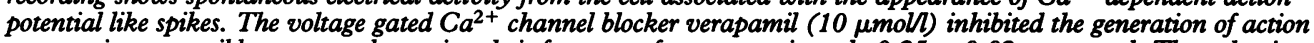
currents in a reversible manner, decreasing their frequency from approximately 0.25 to 0.02 per second. The reduction in frequency of unitary current events results in a decrease in total current amplitude during exposure to verapamil as seen in the figure. 


\section{Discussion}

Persistent hyperinsulinaemic hypoglycaemia of infancy (PHHI) is one of the most difficult of metabolic problems to manage in paediatric medicine. A variety of descriptive clinical terms has been applied to the condition; that most frequently used is 'pancreatic nesidioblastosis'. Milner ${ }^{27}$ has provided a comprehensive review of the history of the condition and the controversies which surround the debate on its pathophysiology.

Although the diagnosis of PHHI is straightforward (by demonstrating, in a single blood sample drawn at the time of hypoglycaemia, the characteristic inappropriate increase in plasma insulin for the degree of glycaemia together with low concentrations of fatty acids and ketone bodies), ${ }^{1}$ in many children the currently available medical treatments may be ineffective, and subtotal or total pancreatectomy may be the only means of controlling the hypoglycaemia. Throughout the period of investigation and initial management, there is the ever present risk of unpredictable and severe episodes of hypoglycaemia, with resultant neurological damage.

Effective medical treatment thus demands a comprehensive understanding of the cellular pathophysiology of PHHI, which has been lacking until recently.

In normal pancreatic $\beta$ cells the electrophysiological events which regulate insulin secretion are coordinated by ATP sensitive potassium $\left(\mathrm{K}^{+}\right.$ATP $)$channels in the $\beta$ cell membrane. ${ }^{11}$ Open $\mathrm{K}^{+}$ATP channel events in resting $\beta$ cells help to maintain the negative intracellular resting membrane potential generated by $\mathrm{Na} / \mathrm{K}-\mathrm{ATPase}$ by allowing potassium efflux. Changes in intracellular ATP concentration after exposure to glucose leads to the closure of the potassium channels, causing membrane depolarisation and the opening of voltage gated calcium channels. This influx of calcium manifests as action potentials which increase the intracellular calcium concentration, thereby providing the signal for initiation of exocytosis and insulin secretion. ${ }^{14}$ Current established pharmacological treatments are able to influence this secretory process where it is not disturbed by the disease process itself. In normal $\beta$ cells both diazoxide and somatostatin cause potassium channel activation, leading to a hyperpolarisation of the membrane potential and termination of the action potentials. ${ }^{11} 12$ Glucagon produces its hyperglycaemic effect by inducing glycogenolysis within the liver. In the isolated $\beta$ cell, however, glucagon increases intracellular cyclic AMP and may increase insulin secretion. The effects of combinations of these three agents are probably more complex. Pharmacological blockade of $\beta$ cell calcium channels which we describe here targets another key process in insulin secretion and provides a welcome addition to our currently limited therapeutic armamentarium in nesidioblastosis.

The results of these in vitro studies upon $\beta$ cells isolated from this infant with nesidioblastosis show that an inappropriate depolarisation of the $\beta$ cell membrane in the face of a low ambient glucose concentration leads to the persistent generation of action potentials associated with voltage gated calcium influx. The resultant increase in intracellular free calcium concentration accounts for the intractable insulin secretion from the PHHI $\beta$ cells. We have shown here in vitro quite clearly that the spontaneous electrical activity associated with insulin secretion in PHHI $\beta$ cells can be reversibly blocked by the L-type calcium channel blocker verapamil. The in vivo correlate of this is an increase in fast tolerance and a modest, though consistent, rise in preprandial blood glucose concentration.

These data, showing the ability to manipulate the process of insulin release pharmacologically by altering ionic activity, represent an important and logical step forward in the application of basic science to the medical management of severe hyperinsulinism in infancy.

The pathological uncoupling of normal electrophysiological activity in PHHI is likely to be a consequence of an abnormal relation between the potassium channel pore protein (KIR 6.2) and the sulphonylurea receptor (SUR), which together constitute the $\mathrm{K}^{+}$ATP channel. ${ }^{13}$ Sulphonylureas are drugs which stimulate the release of insulin by binding the SUR and inducing closure of $\mathrm{K}^{+}$ATP channels. The SUR is a member of the ATP binding cassette or traffic ATPase superfamily, with multiple membrane spanning domains and two nucleotide binding folds. ${ }^{18}$ Point mutations in the SUR gene resulting in truncation of nucleotide binding fold 2 (NBF-2) have been described in familial PHHI. ${ }^{19}$ If, by analogy with cystic fibrosis, ${ }^{28} 29$ the SUR is involved in the trafficking of $\mathrm{K}^{+}$ATP channels or the regulation of $\mathrm{K}^{+}$ATP channel function, then it is reasonable to speculate that a mutation in the gene encoding the protein could lead to altered $\mathrm{K}^{+}$ATP channel activity and persistent $\beta$ cell depolarisation which will eventually result in insulin secretion.

Many questions still remain to be answered. The use of modern molecular biological and electrophysiological technologies has allowed considerable progress in our understanding of the pathophysiology of PHHI, and collaborative studies are under way in our laboratories to match clinical phenotype with electrophysiological phenotype and genotype. The possibility of linkage of the PHHI locus in this patient to that of Axenfeld's anomaly poses a further tantalising question.

We suggest that it is now extremely important to mount prospective collaborative studies on all resected pancreases to explore these concepts further and to undertake linkage analysis on affected families to ensure that non-SUR mutations are not missed. Knowledge of the molecular physiology of the $\beta$ cells in individual cases and the mechanisms and magnitude of their responses to pharmacological agents in vitro will allow specific treatments to be 'designed' for those children who prove refractive to diazoxide, somatostatin, or partial pancreatectomy, and will also aid clinical decision making with regard to the need or otherwise for a further pancreatic resection. 
Questions may surround the long term use of calcium channel blocking agents because of effects on other organs whose function depends critically on the state of membrane depolarisation and calcium influx. A decision was taken in this patient to use nifedipine rather than verapamil because it has less effect on myocardial function, and no specific side effects were noted in this case. More work is needed to define the place of calcium channel blockade in the routine management of PHHI.

\section{CONCLUSIONS}

Electrophysiological studies in isolated $\beta$ cells from a preterm infant with severe hyperinsulinism have focused on the fundamental importance of ionic events as the final common pathway for the initiation of insulin secretion. The demonstration in vitro of the ability to modulate calcium dependent action potentials by a calcium channel blocking agent led to the successful use for the first time of a novel treatment, nifedipine. Our approach offers new and exciting opportunities to understand not only the pathophysiology of PHHI, but to consider the targeting of specific treatments to individual infants.

We thank Dr C Spratt for referring the infant to Great Ormond Street Hospital, Professor Lewis Spitz for his surgical management, and Dr Michael Dillon for essential advice on the use of nifedipine. $\mathrm{KIL}$ is the recipient of a Wellcome Trust Advanced Training Fellowship CK holds a University of Sheffield Research Scholarship. Support of the British Diabetic Association (MJD, RFLJ) and Wellcome Trust (KJL, MJD) is acknowledged.

\section{See annotation on $p 369$.}

Aynsley-Green A. Nesidioblastosis of the pancreas in infancy. In: Randle PJ, Steiner DF, Whelan WJ, eds Carbohydrate metabolism and its disorders. London: Academic Press, 1981: 181-204.

Cornblath M, Schwartz R. Disorders of carbohydrate metabo lism in infancy, 2nd ed. Philadelphia: W B Saunders, 1976.

3 Soltesz G. Aynsley-Green A. Hyperinsulinism in infancy and childhood. In: Russi EW, Seger R, Laron Z, eds. Advances in internal medicine and paediatrics. Berlin Springer-Verlag, 1984: 151-202.

4 Glaser B, Hirsch HJ, Landau H. Persistent hyperinsulinaemic hypoglycaemia of infancy: long-term octreotide treatment without pancreatectomy. $\Im$ Paediatr 1993; 123: 644-50.

5 Thornton PS, Alter CA, Levitt Katz LE, Baker L, Stanley CA. Short- and long-term use of octreotide in the treatment of congenital hyperinsulinism. $\mathcal{F}$ Paediatr 1993;123 $637-43$

6 Spitz L, Bhargava RK, Grant DB, Leonard JV. Surgical reatment of hyperinsulinaemic hypoglycaemia in infancy and childhood. Arch Dis Child 1992; 67: 201-5.

7 Gould VE, Memoli VA, Dardi LE, Gould NE. Nesidiodysplasia and nesidioblastosis of infancy.
Ultrastructural and immunochemical analysis of islet cell alterations with and without associated hyperinsulinism. Scand $\mathcal{F}$ Gastroenterol 1981; 16 (suppl 70): 129-42

8 Aynsley-Green A, Polak JM, Bloom SR, et al Nesidioblastosis of the pancreas: definition of the syndrome and the management of the severe neonatal hyperinsulinaemic hypoglycaemia. Arch Dis Child 1981; 56: 496-508.

9 Kaiser N, Corcos AP, Tur-Sinai A, et al. Regulation of insulin release in persistent hyperinsulinaemic hypoglycaemia of infancy studied in long term culture of pancreatic tissue. Diabetologia 1990; 33: 482-8.

10 Ashcroft FM, Harrison DE, Ashcroft SJH. Glucose induces closure of single potassium channels in isolated rat beta cells. Nature 1984; 312: 446-8.

11 Dunne MJ, Peterson OH. Potassium selective ion channels in insulin secreting cells: physiology, pharmacology and their role in stimulus secretion coupling. Biochim Biophys their role in stimulus sec

12 Ashcroft FM, Proks P, Smith PA, Ammala C, Bokvist K, Rorsman P. Stimulus secretion coupling in pancreatic beta cells. $\mathcal{f}$ Cell Biochem 1994; 55S: 54-65.

13 Inagaki N, Gonoi T, Clement JP, et al. Reconstitution of $\mathrm{I}_{\mathrm{K}} \mathrm{ATP}$ : an inward rectifier subunit plus the sulfonylurea receptor. Science 1995; 268: 423-6.

14 Wollhelm CB, Sharp GWG. Regulation of insulin release by calcium. Phys Rev 1981; 61: 914-73.

15 Boyd AE. The role of ion channels in insulin secretion. 7 Cell Biochem 1992; 48: 234-41.

16 Glaser B, Chiu KC, Anker R, et al. Familial hyperinsulinism maps to chromosome $11 \mathrm{pl}$ 4-15.1, $30 \mathrm{cM}$ centromeric to the insulin gene. Nature Genetics 1994; 7: 185-9.

17 Thomas PM, Cote GJ, Hallman DM, Matthew PM. Homozygosity mapping to chromosome $11 \mathrm{p}$ of the gene for familial persistent hyperinsulinaemic hypoglycaemia in infancy. Am $\mathcal{f}$ Hum Genet 1995; 56: 416-21.

18 Aguilar-Bryan L, Nichols CG, Wechsler SW, et al. Cloning of the $\beta$-cell high-affinity sulfonylurea receptor: a regulator of insulin secretion. Science 1995; 268: 423-6.

19 Thomas PM, Cote GJ, Wohlik N, et al. Mutations in the sulfonylurea receptor gene in familial persistent hyperinsulinaemic hypoglycaemia of infancy. Science 1995; 268: insulina.

20 Squires PE, James RFL, London NIL, Dunne MJ. ATP induced intracellular calcium signals in isolated human insulin secreting cells. Pflugers Arch 1994; 427: 181-3.

21 Dunne MJ. Phorbol myristate acetate and ATP-sensitive potassium channels in insulin secreting cells. Am $\mathcal{F}$ Physiol 994; 267: C501-6.

22 Hoskins HD, Shaffer RN. Reigers syndrome: a form of iridocorneal mesodermal dysgenesis. $\mathcal{f}$ Paediatr Ophthalmol 1972; 9: 26-30.

23 Goosens A, Gepts W, Saudubray J-M, et al. Diffuse and focal nesidioblastosis. A study of 24 patients with persistent hyperinsulinaemic hypoglycaemia. Am $\mathcal{f}$ Surg Pathol 1989; 13: 766-75.

24 Rorsman P, Arkhammar P, Bokvist $\mathrm{K}$, et al. Failure of glucose to elicit a normal secretory response in fetal pancreatic $\beta$-cells results from glucose insensitivity of the ATP-regulated $\mathrm{K}^{+}$channels. Proc Natl Acad Sci USA 989; 86: 4505-9.

25 Schwartz J-L, Wealing GAR, Whitfield JF, Braaten JT. Long-term culture of neonatal rat pancreatic endocrine cells as model for insulin-secretion and ion channel studies. Diabetes 1990; 39: 1353-60.

26 Dunne MJ, Kane C, Squires PE, Lindley KJ, Johnson PRV, James RFL. Persistent neonatal hyperinsulinaemic hypoglyce emia in humans involves a defect in pancreatic $\beta$-cell K ${ }^{\dagger}$ channels [abstr]. $\mathcal{F}$ Physiol (Lond) 1995; 489P: 7-8S.

27 Milner RDG. Nesidioblastosis unravelled. Arch Dis Child 1996; 74: 369-72.

28 Sheppard DN, Rich DP, Ostedgaard LS, Gregory RI Smith AE, Welsh MJ. Mutations in CFTR associated with mild disease form $\mathrm{Cl}^{-}$channels with altered pore properties. Nature 1993; 362: 160-4.

29 Denning GM, Anderson MP, Amara JF, Marshall J, Smith AE, Welsh MJ. Processing of mutant cystic fibrosis transmembrane conductance regulator is temperature sensitive. Nature 1992; 358: 761-4. 